\title{
Ammonium Ion Mediated Resorcarene Capsules: ESI-FTICRMS Study on Gas-Phase Structure and Ammonium Ion Affinity of Tetraethyl Resorcarene and Its Per-Methylated Derivative
}

\author{
Marko Mäkinen and Pirjo Vainiotalo \\ Department of Chemistry, University of Joensuu, Joensuu, Finland \\ Maija Nissinen and Kari Rissanen \\ Department of Chemistry, University of Jyväskylä, Jyväskylä, Finland
}

\begin{abstract}
The ammonium ion binding affinities of tetraethyl resorcarene (1) and its per-methylated derivative (2) were studied by electrospray ionization Fourier transform ion cyclotron resonance (ESI-FTICR) mass spectrometry. Ten different ammonium ions were tested as guests for the resorcarenes. A strong tendency for complex formation was observed with all ammonium ions of size and charge distribution suitable for noncovalent interactions with the cavities of the resorcarene hosts $\mathbf{1}$ and $\mathbf{2}$. Although differences in ammonium ion affinities were observed between $\mathbf{1}$ and $\mathbf{2}$ due to the dissimilar conformations, the overall tendency was that increase in the degree of substitution and the length of carbon chain of the ammonium cation facilitated the complex formation until the sterical hindrance impeded the complexation. Dimeric as well as monomeric ammonium ion complexes were formed with resorcarene $\mathbf{1}$, but resorcarene $\mathbf{2}$ was unable to form the dimeric capsules because of the lack of $\mathrm{H}$-bond donor possibilities. The nature of binding of the guest was further investigated with ion-molecule reactions and by determination of the single crystal X-ray structure of host 1 complexed with tetramethyl ammonium bromide. (J Am Soc Mass Spectrom 2003, 14, 143-151) (C) 2003 American Society for Mass Spectrometry
\end{abstract}

$\mathrm{N}$ oncovalent interactions are a topic of great interest in the world of science today, owing to their governing role in recognition processes both in the biological systems and in synthetic hostguest complexes. The resorcarenes are an excellent example of a class of novel, versatile synthetic host compounds. In addition to their easy availability they have several other interesting properties, such as rigid molecular skeleton, a number of possible conformations and possibility for inter- and intramolecular hydrogen bonding [1]. Resorcarenes are widely used as building blocks for larger supramolecular structures such as cavitands and carcerands [2], as surfacing layer material on gold [3] and thin films [4], at the air-water interface [5], and as hosts in host-guest chemistry. Resorcarenes are specially mentioned as the hosts for quaternary ammonium compounds and appear to be the strongest known complexing agents

Published online January 6, 2003

Address reprint requests to Dr. P. Vainiotalo, Department of Chemistry, University of Joensuu, P.O. Box 111, 80101 Joensuu, Finland. E-mail: Pirjo.Vainiotalo@joensuu.fi for methyl ammonium derivatives [6]. An excellent example of this is their binding of acetylcholine, a neurotransmitter substance at the muscle synapse [7, 8]. In addition to methyl ammonium derivatives, resorcarenes also bind several other guests; the forces that affect the complex formation of resorcarenes are purely noncovalent, such as hydrogen bonding, cation- $\pi$ and $\mathrm{CH}-\pi$ interactions [9]. Large resorcarene-based assemblies even bind fullerenes [10]. Overviews have been published on resorcarenes in general and on their host-guest chemistry [1, 11]. Recently, several articles on guest-controlled dimerization of resorcarene derivatives have been published, showing the influence of the guest on the complex formation $[12,13]$.

Here we report on the complex formation of tetraethyl resorcarene 1 and its per-methylated derivative 2 with ammonium ions differing in degree of substitution. The aim of the study was to clarify, by mass spectrometric means, the correspondence between ammonium ion structure and the capability of the ions to form complexes. The nature of the complexes and the binding was evaluated.

The two host compounds chosen for investigation 


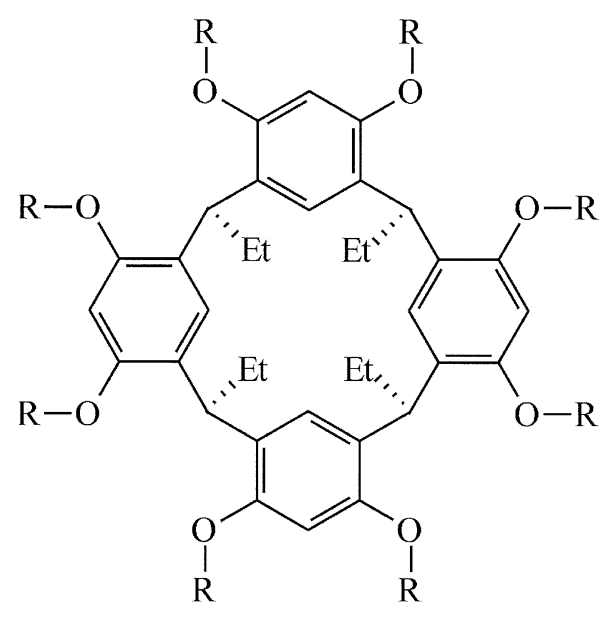

\section{Resorcarene $\mathbf{R}$ $1 \quad$ H}

Figure 1. The two resorcarenes of the study.

are depicted in Figure 1. The three-dimensional structure of $\mathbf{1}$ is crown-like $C_{4}$, the hydroxyl groups are forming the upper rim. In addition, the flip-flop nature of the $\mathrm{H}$-bonds between adjacent resorcinol hydrogens has been suggested [14]. Compound 2 was included in the investigation to clarify the influence of the structural modification on complexation. The conformation of $\mathbf{2}$ is boat-like $C_{2 \mathrm{v}}$, and acting as a H-bond donor is impossible. The properties and behavior of $\mathbf{1}$ and $\mathbf{2}$ as host differed significantly, as was clearly observed in the mass spectra. With both compounds the ammonium guests were presumably located in the interior of the skeleton, inside the $\pi$-basic cavity. Proof of this was also obtained from single crystal X-ray study of the complex of resorcarene 1 with $(\mathrm{Me})_{4} \mathrm{~N}^{+} \mathrm{Br}^{-}$.

The amounts of ammonium ion complexes formed were determined from the relative intensities of the corresponding peaks present in the mass spectra. Although mass spectrometric methods are not entirely suited for quantifying complex formation, several reports of MS results show excellent correspondence with the properties of the species in solution and with results obtained by other methods [15]. Differences in ionization efficiencies and mass discrimination effects could pose a problem. According to Ralph et al. [16], however, ionization efficiency and mass discrimination effects are expected to be limited for inclusion complexes of a large host with a relatively small charged guest and can be neglected. The influence of the solvation energy has been studied by Leize et al; they reported that the ESI-MS yielded a true image of the proportions of different species of alkali metal complexes present in thermodynamical equilibrium in solution [17]. In addition, mass spectrometry is a fast and accurate method of analysis and provides easily gathered but dependable stoichiometric information about cationic species. Be- cause ESI is a gentle ionization technique, which does not actually create ions but transfers them from liquid phase to gas phase, the ESI-MS results are assumed to reflect the complexation phenomena in the liquid state.

\section{Experimental}

\section{Mass Spectrometric Studies}

Samples. The synthesis and characterization of $\mathbf{1}$ have been reported earlier [9a, 18] and the corresponding information for 2 will be reported elsewhere. All commercial solvents and reagents were used without additional purification. Solvents were pure HPLC grade and were purchased from Sigma-Aldrich chemical company (Sigma-Aldrich, Gillingham, UK). The stock solutions of $\mathbf{1}$ and $\mathbf{2}$ were prepared by dissolving $\mathbf{1}$ in acetonitrile and $\mathbf{2}$ in chloroform. Final sample solutions were made by methanol dilution, leading to final sample concen-

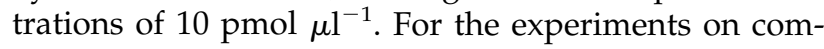
plex formation, all sample solutions contained an equimolar 1:1 ratio of host to guest. The ammonium ions were introduced to the sample solution as hydrochlorides dissolved in water. In competitive complex formation experiments all the participating ammonium ions were present in equimolar concentration.

Equipment. All mass spectrometric experiments were made on the Bruker BioApex 47e Fourier transform ion cyclotron resonance mass spectrometer (Bruker Daltonics, Billerica, MA). The instrument is equipped with an Infinity cell located inside a 4.7 tesla $160 \mathrm{~mm}$ bore superconducting magnet (Magnex Scientific Ltd., Abingdon, UK). Ions are produced in an external electrospray ion source (Analytica of Branford Inc., Branford, CT) and focused with an RF-only hexapole ion guide. The vacuum system is upheld by rotary vacuum pumps; the ultra high vacuum required (approximately $5 \times 10^{-10}$ torr in the cell) was accomplished with turbo pumps supplied by Edwards (Edwards High Vacuum International, Crawley, UK). Normal operating conditions were as follows: The sample was introduced through a syringe infusion pump (Cole-Parmer 74900 series, Cole-Parmer Instrument Company, Vernon Hills, IL) at a flow rate between 35 and $60 \mu \mathrm{l} \mathrm{h}^{-1}$; heated nitrogen $\left(225^{\circ} \mathrm{C}\right)$ was used as a counter-current drying gas. Ion source voltages were invariable, $+3.5 \mathrm{kV}$ to cylinder and end plate. The external capillary voltage was adjusted from +3.5 to $+5.0 \mathrm{kV}$; however, the average value was $+4 \mathrm{kV}$. Both external source and internal electrospray parameters were regulated separately in each experiment to acquire maximum signal. Each spectrum was a collection of 16 scans. The measurements and data handling were made by Bruker XMASS software version 5.0.6.

In ion-molecule reactions the neutral reagent was introduced to the cell via a variable leak inlet valve and the pressure was allowed to rise to $5 \times 10^{-8}$ torr. Ions generated in the external ESI source and transferred to 
the cell were collisionally cooled in the ICR cell and isolated using the CHEF technique [19] and they were allowed to react with neutral reagent with delay times from $1 \mathrm{~s}$ up to $30 \mathrm{~s}$.

Crystallographic Data. Crystallographic data for $\mathrm{C}_{36} \mathrm{H}_{40} \mathrm{O}_{8} \cdot \mathrm{C}_{4} \mathrm{H}_{12} \mathrm{~N}^{+} \mathrm{Br}^{-} \cdot 2 \quad \mathrm{H}_{2} \mathrm{O}$ were obtained with a Nonius Kappa CCD diffractometer at $173.0 \pm 0.1 \mathrm{~K}$ using graphite monochromated $\mathrm{MoK}_{\alpha}$ radiation $\left[\lambda\left(\mathrm{MoK}_{\alpha}\right)=0.71073 \AA\right]$. A colorless crystal of size $0.10 \times$ $0.10 \times 0.15 \mathrm{~mm}$ was obtained from an aqueous mixture of methanol and ethanol. Monoclinic space group $\mathrm{P}$ $2{ }_{1} / \mathrm{m}$ (No. 14), $a=10.9575(6), b=17.980(1), c=$ 11.1525(6) $\AA, \beta=116.067(3)^{\circ}, V=1973.7(2) \AA^{3}, Z=2$, $M_{\mathrm{r}}=790.77 \mathrm{~g} \cdot \mathrm{mol}^{-1} .10031$ reflections collected, of which 4738 were independent $\left(R_{\text {int }}=0.0538\right) ; 3306$ reflections $[I>2 \sigma I]$ were used in refinement. The CCD data were processed with Denzo-SMN v0.93.0 [20]. Reflections were corrected for Lorentz polarization effects; absorption correction was made but not used in the final refinement $\left[\mu\left(\mathrm{MoK}_{\alpha}\right)=1.08 \mathrm{~mm}^{-1}\right.$, maximum and minimum transmission 89.81 and $85.26 \%$, respectively]. The structure was solved by direct methods [21] and refined on $F^{2}$ by full-matrix least-squares techniques [22]. Hydrogen atoms were located from a difference Fourier map but refined as riding atoms in the final refinement, with the exception of hydrogen atoms of the water molecule, which were refined freely. The atomic displacement factors of all hydrogens were fixed to 1.2 or 1.5 times the atomic displacement factors of carbon. $R=0.0568, \mathrm{w} R=0.1093$ for data $I>2 \sigma I$ and $R=0.0963, \mathrm{w} R=0.1240$ for all data, $\mathrm{GOF}=1.031$.

\section{Results and Discussion}

Ten ammonium ions differing in degree of substitution and length of the carbon chain were applied as possible guests (Scheme 1). At first, all ammonium ions were measured separately with both resorcarenes to clarify the effect of the ammonium ion structure on the overall tendency to form complexes. To ignore the influence of variable experimental conditions, some of the ammonium ions were measured simultaneously. This entailed the measurement of competitive complex formation between ammonium ions. The relative amounts of complexes formed were obtained from the corresponding peak intensities.

\section{Complex Formation}

The basic spectra of the methanolic sample solution of $\mathbf{1}$ with the ammonium ions show peaks representing both 1:1 and 2:1 resorcarene-ammonium ion complexes. Figure 2 presents the mass spectrum obtained when an equivalent amount of tetramethyl ammonium chloride was added to the sample solution of 1 . The peak at $\mathrm{m} / \mathrm{z}$ 674 corresponds to the monomer $\left[\mathrm{M}+\left(\mathrm{CH}_{4}\right)_{4} \mathrm{~N}\right]^{+}$, while $m / z 1274$ represents the dimeric complex $[2 \mathrm{M}+$ $\left.\left(\mathrm{CH}_{4}\right)_{4} \mathrm{~N}\right]^{+}$. Reflecting their probable structure these

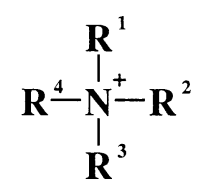

TeM: $\mathrm{R}^{1}=\mathrm{R}^{2}=\mathrm{R}^{3}=\mathrm{R}^{4}=\mathrm{CH}_{3}$

TrM: $\mathrm{R}^{1}=\mathrm{R}^{2}=\mathrm{R}^{3}=\mathrm{CH}_{3}, \mathrm{R}^{4}=\mathrm{H}$

DM: $\quad \mathrm{R}^{1}=\mathrm{R}^{2}=\mathrm{CH}_{3}, \mathrm{R}^{3}=\mathrm{R}^{4}=\mathrm{H}$

MM: $\quad \mathrm{R}^{1}=\mathrm{CH}_{3}, \mathrm{R}^{2}=\mathrm{R}^{3}=\mathrm{R}^{4}=\mathrm{H}$

TeE: $\quad \mathrm{R}^{1}=\mathrm{R}^{2}=\mathrm{R}^{3}=\mathrm{R}^{4}=\mathrm{CH}_{2} \mathrm{CH}_{3}$

TrE: $\quad \mathrm{R}^{1}=\mathrm{R}^{2}=\mathrm{R}^{3}=\mathrm{CH}_{2} \mathrm{CH}_{3}, \mathrm{R}^{4}=\mathrm{H}$

DE: $\quad \mathrm{R}^{1}=\mathrm{R}^{2}=\mathrm{CH}_{2} \mathrm{CH}_{3}, \mathrm{R}^{3}=\mathrm{R}^{4}=\mathrm{H}$

ME: $\quad \mathrm{R}^{1}=\mathrm{CH}_{2} \mathrm{CH}_{3}, \mathrm{R}^{2}=\mathrm{R}^{3}=\mathrm{R}^{4}=\mathrm{H}$

MP: $\quad \mathrm{R}^{1}=\mathrm{CH}_{2} \mathrm{CH}_{2} \mathrm{CH}_{3}, \mathrm{R}^{2}=\mathrm{R}^{3}=\mathrm{R}^{4}=\mathrm{H}$

TeP: $\quad \mathrm{R}^{1}=\mathrm{R}^{2}=\mathrm{R}^{3}=\mathrm{R}^{4}=\mathrm{CH}_{2} \mathrm{CH}_{2} \mathrm{CH}_{3}$

Scheme 1. Ammonium ions applied as guests.

dimeric 2:1 complexes are called "capsules". The intensities obtained for the capsules were surprisingly high, sometimes even higher than those of the corresponding monomers, which indicates the strong tendency for capsule formation. Other, usually minor peaks in the mass spectra were caused by alkali metal cations: sodium and potassium complexes were detected at $\mathrm{m} / \mathrm{z}$ 623 and 639, respectively.

The amount of ammonium ions present in the solution affects the capsule formation process. This is seen in Figure 3 where the proportion of capsules in the total ion current is presented as a function of the relative concentrations of host and guest (tetramethyl ammonium ion). The proportion of capsule is higher $(>80 \%)$ with smaller concentrations of guest. In a competitive situation with small concentrations of guests, when free resorcarenes are competing for the formed monomeric complexes and the free ammonium ions, the capsule

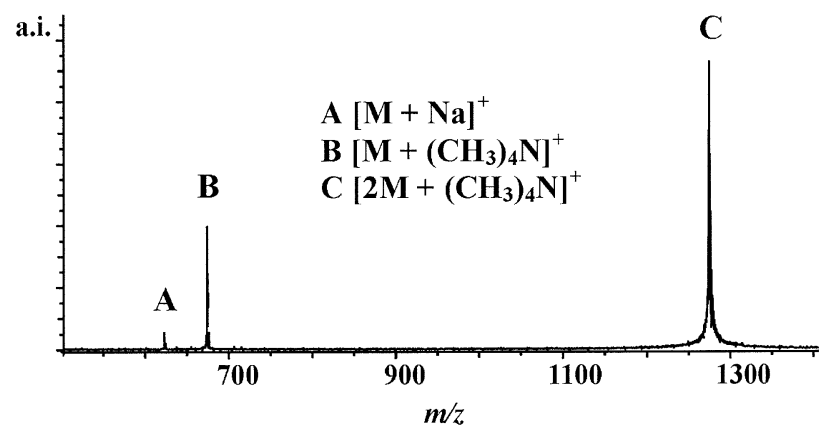

Figure 2. ESI spectra of resorcarene 1 with $\left[\left(\mathrm{CH}_{3}\right)_{4} \mathrm{~N}\right]^{+}$. 


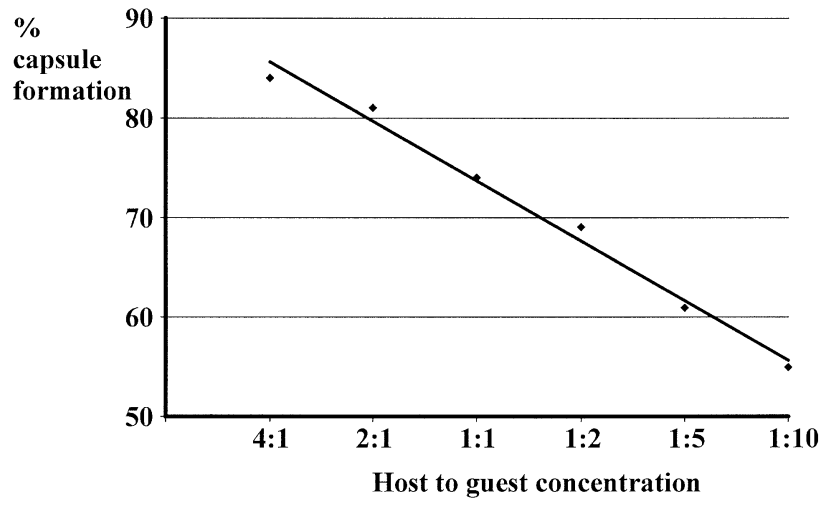

Figure 3. Relationship between capsule formation (\%) and relative host-guest concentration.

formation is dominant. The reason for this is that, after monomeric complexation, a great amount of free resorcarene still remains for capsule formation. Thus, the monomeric resorcarene complex is an efficient capsule former: The tendency to form capsules increases when a surplus of "free" resorcarene is present. This is in good accord with the theory of guest-controlled dimerization, according to which the amount of guest controls the formation of dimer and the cooperation of both $\mathrm{H}$ bonding and other weak host-guest interactions leads to capsule formation [12]. The overall capsule formation with tetramethyl ammonium as guest was notable with all concentrations tested: Capsules typically comprised over $50 \%$ of the total ion abundances. H-bonded solvent-free capsules of $\mathbf{1}$ were also observed in the presence of other ammonium ion guests, with the exception of tetrapropylammonium ion.

It can be assumed that in the dimeric gas-phase capsule the guest is located in the closed cavity between the resorcarene units and is, therefore, unreactive to neutral reagent. In the monomeric complex, in turn, the guest is located in the more open cavity of the resorcarene and is reactive to neutral reagent. To clarify the location of the guest in the monomeric and dimeric complexes, host exchange from trimethyl ammonium ion to dimethyl ammonium ion was attempted. The monomeric complex exchanged its guest while the dimeric capsule did not. This result strongly suggests that the location of the guest inside the capsule is as assumed.

The forces holding the capsule structure together probably are direct intermolecular H-bonds between the facing resorcarene units. These solvent-free gasphase capsules are formed either directly in solution without participation of solvent molecules or with linking via solvent molecules. However, to our knowledge no evidence of such solvent-free capsules has been obtained, either in solution or in solid state, where the resorcarenes forming the capsules are always mediated by hydrogen bonding to solvent molecules [13]. It seems likely, therefore, that directly hydrogen bonded capsules are formed during the ESI process. The forma- tion may proceed as follows: In solution, resorcarenes are linked via hydrogen bonding to solvent molecules. In the ESI process the solvent molecules evaporate because of drying gas and the relative closeness of the resorcarene units facilitates direct intermolecular $\mathrm{H}$ bonding. The multiple hydrogen bonding is strong enough to maintain the capsule structure during the desolvation process and further in the gas phase.

The significance of the intermolecular $\mathrm{H}$-bonding for the capsule formation was confirmed with resorcarene 2. When tetramethyl ammonium chloride was added to the sample solution of $\mathbf{2}$, the main peak in the mass spectrum represented the monomeric complex and no formation of capsules was observed.

The general appearance of all spectra generated from the solutions of resorcarene $\mathbf{1}$ plus ammonium ion was similar, although the amount of the complexes varied. Corresponding 1:1 and 2:1 complexes of 1 were found with almost all the ammonium ions investigated; exceptions are noted below. Alkali metal cations were usually present as contaminants causing additional peaks in the spectra.

The single crystal X-ray structure of the tetramethyl ammonium complex of $\mathbf{1}$ was obtained for purposes of comparison in the mass spectrometric gas-phase and molecular modeling studies. In solid state, resorcarene 1 forms a 1:1 inclusion compound with tetramethyl ammonium bromide (Figure 4), i.e., under our crystallization conditions in aqueous methanol-ethanol mixture no capsule formation occurs. The cation is situated in the cavity of the host, while interestingly, the anion is included at the lower rim between the ethyl chains, via weak C-H. . . Br ${ }^{-}$hydrogen bonds [Br1 . .C29 = 3.993(3) and Br1. . .C31 = 4.081(3) $\AA$. Due to the symmetry of the crystal lattice (the asymmetric unit contains only half of the host molecule), there exists all together four weak $\mathrm{CH}$. . Br hydrogen bonds (Figure 5). The weak interactions holding the cation in the cavity are $\mathrm{C}-\mathrm{H} . . . \pi$ interactions from C39 of the cation to the lower rim of the aromatic rings; distances from C39 to centroids of the aromatic rings vary from 3.62 to $3.87 \AA$.

In complexation with tetramethyl ammonium bromide, the host 1 adopts a nearly symmetrical crown conformation [dihedral angles between opposite aromatic rings 70.91(7) and 74.1(1); distances between their centroids 6.80(1) and 6.87(1) $\AA$ ], which is stabilized by a circular array of four hydrogen bonds between adjacent $\mathrm{OH}$-groups [O11. . O $20=2.721(3)$ and O13. . O $4=2.636(3) \AA]$. The slightly deformed crown conformation of the uncomplexed host [17] changes in response to the complexation of the guest. The inclusion of the cation in the cavity and the simultaneous inclusion of the anion at the lower rim induces a change from the slightly deformed crown of the free host to the nearly perfect $\mathrm{C} 4$ crown observed here in $\left[\mathrm{N}\left(\mathrm{CH}_{3}\right)_{4} 1\right] \mathrm{Br}$. Reversed and larger conformational change from crown to boat is typical for resorcarenes upon disruption of the circular H-bonding [16].

Although a few crystal structures of solvent-medi- 


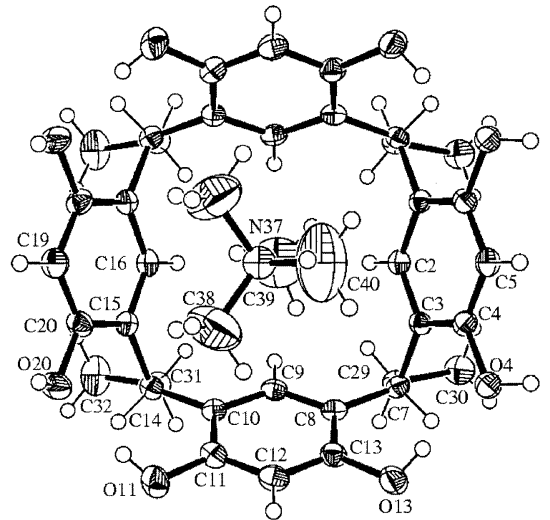

(a)

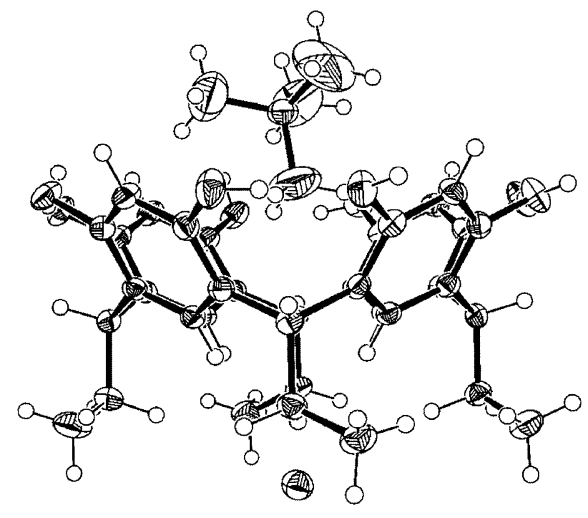

(b)

Figure 4. Top (a) and side (b) views of the solid state $\left(\mathrm{CH}_{3}\right)_{4} \mathrm{~N}^{+} \mathrm{Br}^{-}$complex of resorcarene 1 showing the crystallographic numbering scheme. Thermal ellipsoids are drawn at the $50 \%$ probability level.

ated capsular, dimeric complexes of resorcarenes with ammonium compounds are known [13], no capsule was formed in our case. Instead, the solvent water molecules mediate the formation of a network of hosts by forming a circular array of cooperative hydrogen bonds between water molecules and hydroxyl groups $\left[\mathrm{O} 4 \ldots \mathrm{O} 100=2.631(3), \mathrm{O} 20 \ldots \mathrm{O} 100^{*}=\right.$ 2.724(3), O100. . O13** = 2.659(3) ̊̊] (Figure 5). Additional hydrogen bonds are formed to bromide anion $[\mathrm{O} 100$. . . Br1 = 3.206(2) $\AA$ ].

\section{Complex Formation Affinity of Methyl Ammonium Ions}

The spectrum of $\mathbf{1}$ with four different methyl ammonium ion guests is shown in Figure 6. Monomeric complexes were formed with all cations, while capsules were formed only with the tri- and tetramethylated species. The overall order of complex formation reflected the substitution in decreasing order tetra $>$ tri $>$ di $\cong$ mono. According to molecular models, all the

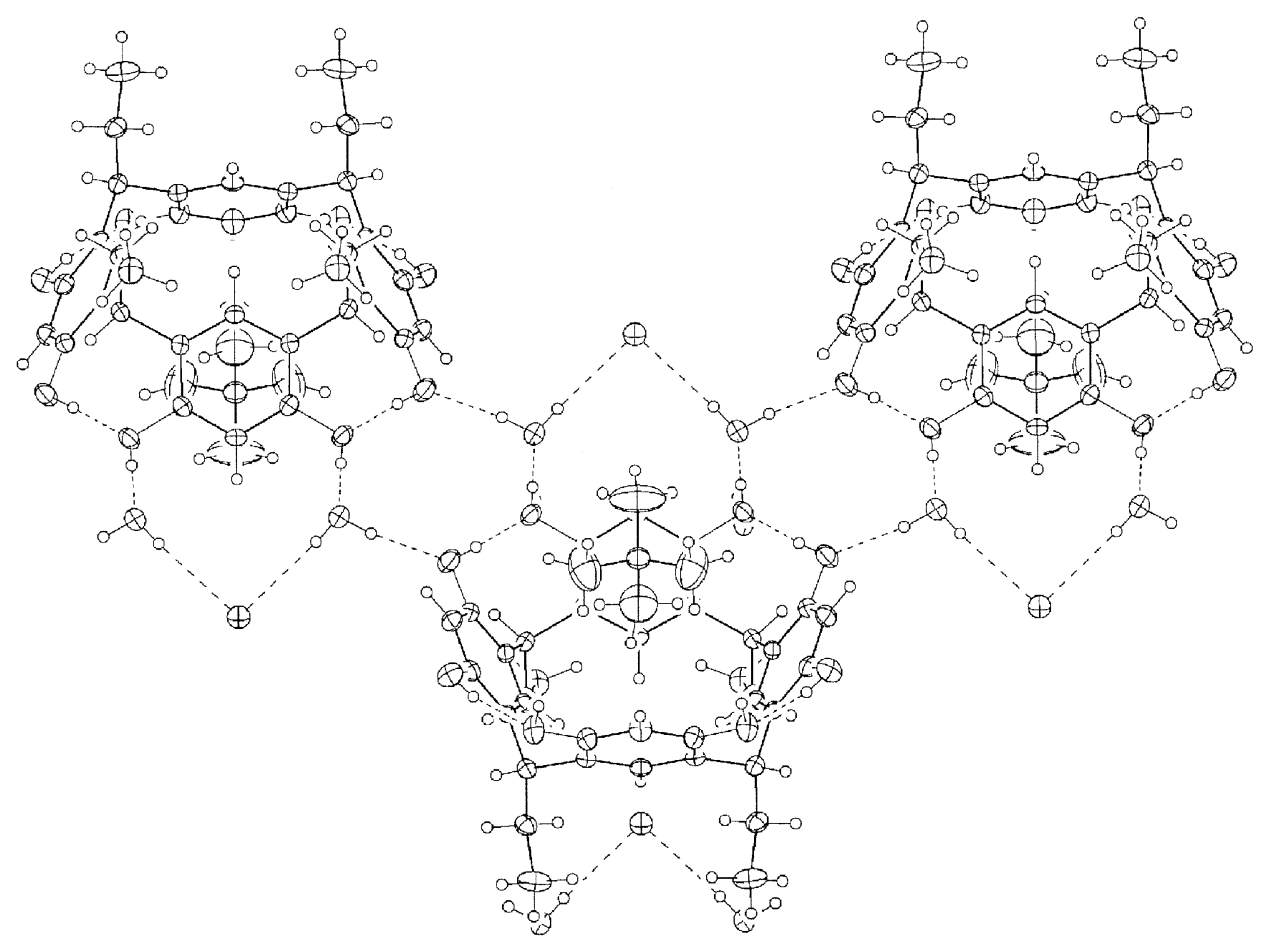

Figure 5. Crystal packing of the solid state complex of $\left(\mathrm{CH}_{3}\right)_{4} \mathrm{~N}^{+} \mathrm{Br}^{-}$of resorcarene 1 showing the cooperative cyclic array of hydrogen bonds. 


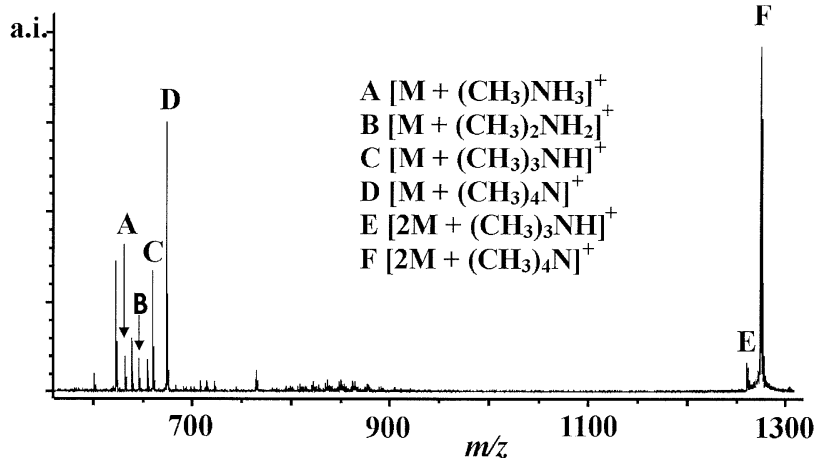

Figure 6. ESI spectra of resorcarene 1 with methyl ammonium ions.

methyl ammonium ions are small enough to fit inside the resorcarene cavity, and the crystal structure of $\mathbf{1}$ with tetramethyl ammonium cation indicates that the forces holding the complex together are $\mathrm{CH}-\mathrm{O}, \mathrm{CH}-\pi$, and cation- $\pi$ interactions. Since the calculations suggest that minimum energy is achieved when one methyl group is pointing towards the cavity, a possible explanation for the complex formation affinity observed is the "statistic effect". With increased degree of methylation the possibility for one methyl group to be oriented towards the cavity also increases. The possibility for one methyl group to be oriented towards the cavity is thus greatest for the tetramethylated ammonium ion, and it has maximum possibilities for interaction. The results of the competitive complexation of methyl ammonium cations showing the dominance of the tetrasubstituted species are presented in Table 1.

Capsule formation occurred only with trimethyl and tetramethyl ammonium ions, of which the tetramethyl ion showed about tenfold tendency for capsule formation. This suggests that the additional methyl groups are, indeed, essential to the formation of capsules. With the cations having lower degrees of

Table 1. Methyl and ethyl ammonium ion competitions in complexations with resorcarenes $\mathbf{1}$ and $\mathbf{2}(\%)$

\begin{tabular}{ccccc}
\hline & TeM & TrM & DM & MM \\
\hline \hline $\mathbf{1}$ & & & & \\
Monomer & 44 & 13 & 3 & 2 \\
Dimer & 35 & 3 & 0 & 0 \\
$\mathbf{2}$ & 23 & 30 & 28 & 19 \\
\hline & $\mathrm{TeE}$ & $\mathrm{TrE}$ & $\mathrm{DE}$ & $\mathrm{ME}$ \\
\hline $\mathbf{1}$ & & & & \\
Monomer & 4 & 7 & 10 & 17 \\
Dimer & 45 & 10 & 2 & 5 \\
$\mathbf{2}$ & 2 & 8 & 30 & 60 \\
\hline
\end{tabular}

substitution, even the tendency to form monomer was lower.

The results for the competitive methyl ammonium ion experiments were completely different with host 2 (Table 1). As mentioned above, capsules did not form at all, and with monomers the binding sequence was altered. The overall tendency to complex formation vis à vis to the degree of methyl substitution was tri $>$ di $>$ tetra $>$ mono. The two parallel resorcinol subunits, forming the broadsides of the boat in 2 , are closer to each other than the resorcinol subunits in the crown conformation of $\mathbf{1}$, and steric effects are introduced. The shape of the tri-, di-, and monomethyl ammonium ions is such that all of them can locate between the parallel resorcinol units. However, the more elongated tri- and dimethyl ammonium ions have a greater possibility to interact with the resorcinol rings than does the monomethyl ammonium ion. The tetramethyl ammonium ion is too bulky to fit between the units. Still, the observed differences in complexation of $\mathbf{2}$ with the methyl ammonium ions are relatively small and no ion exhibits a strong tendency to form complexes.

\section{Complex Formation Affinity of Ethyl Ammonium Ions}

The significance of steric factors is sharply revealed in the complex formation of the ethyl ammonium ions-in drastic overall decrease in the signal intensities relative to those for the complexes with methyl ammonium ions. With 1 the possibility to form complexes is still notable, nevertheless, with the overall order being tetra $>$ mono $>$ tri $>$ di (Table 1 ). The reasons are as follows: Monoethyl ammonium is of perfect shape to fit inside the cavity but is a weak capsule former. Diethyl and triethyl ammonium ions fit inside the cavity, but the triethyl ammonium dominates over diethyl ammonium owing to the better capsule forming capability. Predominantly dimeric capsules were observed with tetraethyl ammonium ion. A similar observation of dimeric capsules has been reported earlier on the basis of NMR measurements [23], and also a crystal structure for the dimeric complex is known [13b].

The complexation of ethyl ammonium ions with 2 differed from that with $\mathbf{1}$ and from the complexation of methyl ammonium ions with 2: Monomeric complex formation was in the order mono $>\mathrm{di}>$ tri $>$ tetra. The reason for this order is stericity, which hinders the complexation. As expected, complex formation with triand tetrasubstituted ions is minor, while the ethyl ammonium monomer complex is the most abundant representing $60 \%$ of the total amount, and the diethyl ammonium monomer next with a proportion of about $30 \%$ (Table 1). The overall intensities for all ethyl ammonium complexes with 2 were low, however, and the complexes dissociated easily. 
Table 2. Primary and quaternary ammonium ion competitions in complexation with resorcarenes $\mathbf{1}$ and $\mathbf{2}(\%)$

\begin{tabular}{cccc}
\hline & MM & ME & MP \\
\hline \hline $\mathbf{1}$ & & & \\
Monomer & 21 & 21 & 29 \\
Dimer & 4 & 14 & 11 \\
$\mathbf{2}$ & 10 & 30 & 60 \\
\hline & TeM & TeE & TeP \\
\hline $\mathbf{1}$ & & & \\
Monomer & 18 & 1 & - \\
Dimer & 79 & 2 & - \\
$\mathbf{2}$ & 94 & 6 & - \\
\hline
\end{tabular}

\section{Effect of Length of the Carbon Chain on Complex Formation}

Monosubstituted methyl-, ethyl-, and propyl ammonium ions were applied as guests in competitive reaction with resorcarene 1 . It was expected that as the length of the carbon chains increases the overall binding also becomes stronger, owing to the increased possibility for binding interactions. As can be seen in Table 2, the tendency for monomeric complex formation was propyl $>$ ethyl $\cong$ amethyl, in accordance with expectation. The situation was slightly different with the capsules: The best capsule former was the ethyl ammonium ion, although the difference in the intensities of the ethyl and propyl ion was minor. When both monomeric and capsule complexes are taken into account the overall order of the complex formation correlates with the length of the carbon chain.

The complex formation affinity with $\mathbf{2}$ was similar to that with 1, but the differences in intensities were sharper (Table 2). The propyl ammonium monomer comprised as much as $60 \%$, indicating strong affinity for complex formation, while the amount of ethyl monomer was about $30 \%$ and the remaining $10 \%$ was methyl monomer.

Competitive complexation studies on hosts $\mathbf{1}$ and $\mathbf{2}$ were also performed with tetrasubstituted ammonium ions. The order in complex formation with $\mathbf{1}$ was methyl $>$ ethyl $\gg$ propyl (Table 2). This is in accordance with the results previously obtained in NMR studies on methyl resorcarene [23] and underlines the significance of the size of the guest for complex formation. In fact, the tetrapropyl ammonium ion is unable to form complexes at all, and just a minor amount of tetraethyl ammonium complexes was observed; tetramethyl ammonium ion mostly forms capsules.

The situation was similar with 2: Tetrapropyl ammonium ion was unable to form complexes and tetramethyl dominated over tetraethyl ammonium ion (Table 2). However, even the complexes that formed were highly unstable: With slight increase in the capillary voltage the respective peaks vanished from the spectra.
Table 3. Competition of $\mathbf{1}$ and $\mathbf{2}$ for ammonium ions (\%)

\begin{tabular}{lccc}
\hline & $\mathbf{1}$ & $\mathbf{1}$ & \\
& monomer & dimer & $\mathbf{2}$ \\
\hline \hline TeM & 15 & 54 & 31 \\
TrM & 6 & 55 & 39 \\
DM & 7 & 13 & 81 \\
MM & 0.5 & 0.5 & 99 \\
TeE & 66 & 34 & 0 \\
TrE & 5 & 13 & 82 \\
DE & 5 & 1 & 94 \\
ME & 0 & 1 & 99 \\
MP & 0 & 4 & 96 \\
TeP & - & - & - \\
\hline
\end{tabular}

\section{Competitive Ammonium Ion Affinity of 1 and 2}

The relative complex formation affinity of $\mathbf{1}$ and $\mathbf{2}$ was evaluated in competition experiments carried out with the ammonium ions (Table 3). As expected, host 1 preferred to form complexes with branched and small methyl ammonium ions, while host $\mathbf{2}$ was an outstanding complex former for elongated ammonium ions. These measurements also suggested that the complex formation occurs in the liquid state: The results are well explained by the different conformational forms of $\mathbf{1}$ and 2 present in solution. Since the results are clearly divergent for the two resorcarenes, the conformational properties, and as well as the sterical factors, must have a significant effect on the complex formation.

\section{Conclusion}

Mass spectrometry is a suitable method for specifying weakly, noncovalently bonded host-guest complexes and provides exact stoichiometric information on gasphase aggregates of multiple species. In this study, ammonium ions were applied as guests for resorcarene hosts $\mathbf{1}$ and 2. The affinity of $\mathbf{1}$ and $\mathbf{2}$ for complex formation with the various ammonium ions was determined.

The following observations were made: (1) Resorcarene $\mathbf{1}$ forms dimeric capsules as well as monomeric complexes, while resorcarene $\mathbf{2}$ forms only monomeric complexes owing to the lack of $\mathrm{H}$-bonding possibilities; (2) host 1 prefers complex formation with small and branched ammonium ions, especially with tetramethyl ammonium, while (3) host 2 prefers complex formation with elongated ammonium ions; (4) the capsule formation process with 1 becomes more efficient with low guest concentrations; (5) as shown by the ion-molecule reactions, in the capsule the guest located inside the capsule structure; (6) as shown by the crystal structure determination of $\mathbf{1} \cdot\left(\mathrm{CH}_{3}\right)_{4} \mathrm{~N}^{+} \mathrm{Br}^{-} \cdot 2 \mathrm{H}_{2} \mathrm{O}$, in the monomeric host-guest complexes the guest is located inside the cavity. The crystal structure also reveals the interesting simultaneous binding of bromide anion between the lower rim ethyl chains.

Further conclusions are the following: (1) Complex formation was observed with all ammonium ion guests 
of suitable size and shape, which means that the steric hindrance of the guest is limiting for the complexation and is controlling the process. (2) As shown by the relationship between the capsule formation and the host to guest concentration, both the monomeric and dimeric host-guest complexation occurs in the liquid phase. (3) Because the conformations of $\mathbf{1}$ and $\mathbf{2}$ differ considerably $\left(C_{4}\right.$ crown and $C_{2 \mathrm{v}}$ boat, respectively), the affinity to form complexes is also dissimilar. Owing to its more open conformational structure, host 2 does not exhibit the same kind of selectivity to guests as $\mathbf{1}$. However, as clearly revealed in the competition experiments, it still readily forms complexes with ions that suitably fit inside the cavity formed by facing resorcinol units. (4) In gaseous state the dimeric capsules of $\mathbf{1}$ with suitable ammonium ions are probably held together by direct intermolecular H-bonds without the linking solvent molecules usually observed in solid-state structures. Because capsules were not formed with all the ammonium ions, it seems that the structure and size of the guest are decisive for their formation; cooperation of both host-guest interaction and intermolecular $\mathrm{H}$-bonding enables the encapsulation. The guest inside the capsule may also stabilize the capsule by electrostatic interactions. Although the mechanism of the capsule formation is unclear, the abundant formation of solvent-free gas-phase capsules with some of the ammonium ions has been indisputably demonstrated by MS methods.

The differences in complex formation affinities between the resorcarenes were highlighted here through ESI-FTICRMS experiments. ESI-MS appears to reflectboth qualitatively and quantitatively-the "true" amount of complexes present in the solution and provides a suitable method for investigating fragile supramolecular complexes.

\section{Acknowledgments}

The authors thank D. Falábu for synthesizing the resorcarenes. PV and MM gratefully acknowledge funding by the Academy of Finland, grant 68194. MN thanks the Academy of Finland for a postdoctoral grant (project no. 100319).

\section{References}

1. Timmerman, P.; Verboom, V.; Reinhoudt, D. N. Resorcinarenes. Tetrahedron 1996, 52, 2663-2704.

2. (a)Tunstadt, L. M.; Tucker, J. A.; Dalcanale, E.; Weiser, J.; Bryant, J. A.; Sherman, J. C.; Helgeson, R. C.; Knobler, C. B.; Cram, D. J. Host-Guest Complexation. 48. Octol Building Blocks for Cavitands and Carcerands. J. Org. Chem. 1989, 54, 1305-1312. (b) Cram, D. J.; Cram, J. M. Container Molecules and Their Guests; The Royal Society of Chemistry:1994; p 87 and references therein.

3. (a) Davis, F.; Stirling, C. J. M. Calix-4-resorcinarene Monolayers and Multilayers: Formation, Structure, and Differential Adsorption. Langmuir 1996, 12, 5365-5374. (b) Schönherr, H.; Vansco, G. J.; Huisman, B-H.; van Veggel, F. C. J. M.; Reinhoudt, D. N. An Atomic Force Microscopy Study of SelfAssembled Monolayers of Calix[4]resorcinarene Adsorbates on $\mathrm{Au}(111)$. Langmuir 1997, 13, 1567-1570. (c) Adams, H.; Davis, F.; Stirling, C. J. M. Selective Adsorption in Gold-Thiol Monolayers of Calix-4-resorcinarenes. Chem. Commun. 1994, 2527-2529. (d) Thoden van Velzen, E. U.; Engbersen, J. F. J.; de Lange, P. J.; Mahy, J. W. G.; Reinhoudt, D. N. Self-Assembled Monolayers of Resorcin[4]arene Tetrasulfides on Gold. J. Am. Chem. Soc. 1995, 117, 6853-6862. (e) Thoden van Velzen, E. U.; Engbersen, J. F. J.; Reinhoudt, D. N. Synthesis of Self-Assembling Resorcin[4]arene Tetrasulfide Adsorbates. Synthesis 1995, 989-997. (f) Huisman, B-H.; Kooyman, R. P. H.; van Veggel, F. C. J. M.; Reinhoudt, D. N. Molecular Recognition by Self-Assembled Monolayers Detected with Surface Plasmon Resonance. Adv. Mat. 1996, 8, 561-564. (g) Faull, J. D.; Gupta, V. K. Selective Guest-Host Association of Self-Assembled Monolayers of Calix[4]resorcinarene. Langmuir 2001, 17, 14701476.

4. (a) Dutton, P. J.; Conte, L. Terbium Luminescence in Langmuir-Blodgett Films of Octafunctionalized Calix[4]resorcinarenes. Langmuir 1999, 15, 613-617. (b) Moreira, W. C.; Dutton, P. J.; Aroca, R. Spectroscopic Characterization and the Effect of Metal Ions on Langmuir-Blodgett Films of Octasubstituted Calix[4]resorcinarenes. Langmuir 1995, 11, 3137-3144. (c) Moreira, W. C.; Dutton, P. J.; Aroca, R. Langmuir-Blodgett Monolayers and Vibrational Spectra of Calix[4]resorcinarene. Langmuir 1994, 10, 4148-4152. (d) Omar, O.; Ray, A. K.; Hassan, A. K.; Davis, F. Resorcinol Calixarenes (Resorcarenes): Langmuir-Blodgett Films and Optical Properties. Supramol. Sci. 1997, 4, 417-421. (e) Santos, J. P.; Zaniquelli, M. E. D.; Dutton, P. J. Calixresorcinarene Complexation of Rare Earth Ions in Liquid Monolayers and Multilayer Langmuir-Blodgett Films. Colloids Surf. A 2002, 605-611. (f) Prus, P.; Pietraszkiewicz, M.; Bilewicz, R. Calix[4]resorcinarene: Molecular Recognition in Langmuir Films. Mater. Sci. Eng. C 2001, 18, 157-159.

5. Kurihara, K.; Ohto, K.; Tanaka, Y.; Ayoama, Y.; Kunitake, T. Molecular Recognition of Sugars by Monolayers of Resorcinol-Dodecanal Cyclotetramer. J. Am. Chem. Soc. 1991, 113, $445-450$.

6. (a) Schneider, H-J.; Güttes, D.; Schneider, U. A Macrobicyclic Polyphenoxide as Receptor Analogue for Choline and Related Ammonium Compounds. Angew. Chem. Int. Ed. 1986, 25, 647-649. (b) Lippmann, T.; Wilde, H.; Pink, M.; Schäfer, A.; Hesse, M.; Mann, G. Host-Guest Complexes between Calix[4]arenes Derived from Resorcinol and Alkylammonium Ions. Angew. Chem. Int. Ed. 1993, 32, 1195-1197. (c) Schneider, H-J.; Güttes, D.; Schneider, U. Host-Guest Complexes with Water-Soluble Macrocyclic Polyphenolates Including Induced Fit and Simple Elements of a Proton Pump. J. Am. Chem. Soc. 1988, 110, 6449-6454.

7. Maelicke, A. Biochemical Aspects of Cholinergic Excitation. Angew. Chem. Int. Ed. 1984, 23, 195-221.

8. (a) Schneider, H-J.; Schneider, U. Inhibition of Choline Acetate Hydrolysis in the Presence of a Macrocyclic Polyphenolate. J. Org. Chem. 1987, 52, 1613-1615. (b) Murayama, K.; Aoki, K. Molecular Recognition Involving Multiple Cation- $\pi$ Interactions: The Inclusion of the Acetylcholine Trimethylammonium Moiety in Resorcin[4]arene. Chem. Commun. 1997, 119-120. (c) Inouye, M.; Hashimoto, K.; Isagawa, K. Nondestructive Detection of Acetylcholine in Protic Media: Artificial-Signaling Acetylcholine Receptors. J. Am. Chem. Soc. 1994, 116, 55175518.

9. (a) Ayoama, Y.; Tanaka, Y.; Sugahara, S. Molecular Recognition of Sugars via Hydrogen-Bonding Interaction with a Synthetic Polyhydroxy Macrocycle. J. Am. Chem. Soc. 1989, 111, 5397-5404. (b) Ayoama, Y.; Tanaka, Y.; Toi, H.; Ogoshi, H. Polar Host-Guest Interaction. Binding of Nonionic Polar Compounds with a Resorcinol-Aldehyde Cyclooligomer as a Lipophilic Polar Host. J. Am. Chem. Soc. 1988, 110, 634-635. (c) 
Kikuchi, Y.; Tanaka, Y.; Sutarto, S.; Kobayashi, K.; Hiroo, T.; Aoyama, Y. Highly Cooperative Binding of Alkyl Glucopyranosides to the Resorcinol Cyclic Tetramer Due to Intracomplex Guest-Guest Hydrogen-Bonding: Solvophobicity/Solvophilicity Control by an Alkyl Group of the Geometry, Stoichiometry, Stereoselectivity, and Cooperativity. J. Am. Chem. Soc. 1992, 114, 10302-10306. (d) Kobayashi, K.; Asakawa, Y.; Aoyama, Y. Complexation of Methylammonium Salts and Sugar-Related Alcohols with Resorcinol Cyclic Tetramer in Water: An Implication of the $\mathrm{CH}-\pi$ Interaction on Polar Guest Binding. Supramolecul. Chem. 1993, 2, 133-135. (e) Kobayashi, K.; Asakawa, Y.; Kikuchi, Y.; Toi, H.; Aoyama, Y. $\mathrm{CH}-\pi$ Interaction as an Important Driving Force of HostGuest Complexation in Apolar Organic Media. Binding of Monools and Acetylated Compounds to Resorcinol Cyclic Tetramer as Studied by ${ }^{1} \mathrm{H}$ NMR and Circular Dichroism Spectroscopy. J. Am. Chem. Soc. 1993, 115, 2648-2654. (f) Konishi, H.; Morikawa, O. Host-Guest Complexation of Octahydroxy[ $\left[1^{4}\right]$ metacyclophanes with Caffeine. Chem. Express 1992, 7, 801-804.(g)Kobayashi, K.; Tominaga, M.; Asakawa, Y.; Ayoama, Y. Binding of Amino Acids in Water to a Highly Electron-Rich Aromatic Cavity of Pyrogallol or Resorcinol Cyclic Tetramer as $\pi$-Base. Tetrahedron Lett. 1993, 34, 5121-5124. (h) Cao, Z.; Murayama, K.; Aoki, K. ThicknessShear-Mode Acoustic Wavesensor for Acetone Vapor Coated with C-ethylcalix[4]resorcinarene and $\mathrm{C}-\mathrm{H} \cdots \pi$ Interactions as a Molecular Recognition Mechanism. Anal. Chim. Acta 2001, 448, 47-58. (i) Murayama, K.; Aoki, K. Multiple Cation- $\pi$ Interactions between the Trimethylammonium Moiety and the Aromatic Rings within a Molecular Complex Formed between 3-Phenylpropionic Acid Choline Ester and Resorcin[4]arene. Chem. Lett. 1998, 301-302. (j) Botta, B.; Monache, G. D.; Ricciardi, P.; Zappia, G.; Seri, C.; Gacs-Baitz, E.; Csokasi, P.; Misiti, D. The Interaction of Resorcin[4]arenes with $\mathrm{Fe}^{\mathrm{III}}$ in Chloroform. Eur. J. Org. Chem. 2000, 841-847.

10. Fox, D.; Drew, M. G. B.; Wilkinson, E. J. S.; Beer, P. D. Cadmium- and Zinc-Directed Assembly of Nano-Sized, Resorcarene-Based Host Architectures which Strongly Bind $\mathrm{C}_{60}$. Chem. Commun. 2000, 391-392.

11. Schneider, H.-J.; Schneider, U. The Host-Guest Chemistry of Resorcinarenes. J. Inclusion Phenom. Mol. Recog. 1994, 19, 67-83.

12. Shivanyuk, A.; Paulus, E. F.; Böhmer, V. Guest-Controlled Formation of a Hydrogen-Bonded Molecular Capsule. Angew. Chem. Int. Ed. 1999, 38, 2906-2908.

13. (a) Murayama, K.; Aoki, K. Resorcin[4]arene Dimer Linked by Eight Water Molecules and Incorporating a Tetraethylammonium Ion: Guest-Driven Capsule Formation via Cation- $\pi$ Interactions. Chem. Commun. 1998, 607-608. (b) Shivanuyk, A.; Rissanen, K.; Kolehmainen, E. Encapsulation of $\mathrm{Et}_{3} \mathrm{~N}^{+}-$ $\mathrm{H} \cdots \mathrm{OH}_{2}$ in a Hydrogen-Bonded Resorcarene Capsule. Chem. Commun. 2000, 1107-1108.

14. Mäkinen, M.; Rissanen, K.; Vainiotalo, P. Alkali Metal Mediated Resorcarene Capsules: An ESI-FTICRMS Study on GasPhase Structure and Cation Binding of Tetraethyl Resorcarene and its Per-Methylated Derivative. J. Am. Soc. Mass Spectrom. 2002, 13, 851-861.

15. (a) Schalley, C. A.; Martín, T.; Obst, U.; Rebek, J., Jr. Characterization of Self-Assembling Encapsulation Complexes in the
Gas Phase and Solution. J. Am. Chem. Soc. 1999, 121, 2133-2138. (b) Schalley, C. A.; Castellano, R. K.; Brody, M. S.; Rudkevich, D. M.; Siuzdak, G.; Rebek, J., Jr. Investigating Molecular Recognition by Mass Spectrometry: Characterization of Calixarene-Based Self-Assembling Capsules Hosts with Charged Guests. J. Am. Chem. Soc. 1999, 121, 4569-4579. (c) Schalley, C. A.; Rivera, J. M.; Martín, T.; Santamaria, J.; Siuzdak, G.; Rebek, J., Jr. Structural Examination of Supramolecular Architectures by Electrospray Ionization Mass Spectrometry. Eur. J. Org. Chem. 1999, 1325-1331. (d) Schalley, C. A. Supramolecular Chemistry Goes Gas Phase: The Mass Spectrometric Examination of Noncovalent Interactions in Host-Guest Chemistry and Molecular Recognition. Int. J. Mass Spectrom 2000, 194, 11-39. (e) Wang, K.; Gokel, G. W. Correlation of Solution and Gas Phase Complexation Assessed by Electrospray Ionization Mass Spectrometry: Application to One-, Two-, and ThreeRing Macrocycles. J. Org. Chem. 1996, 61, 4693-4697. (f) Bartoszek, M.; Graubaum, H.; Wendland, D.; Dambovski, R. Investigation of Metal-Ion Complexes of Triazino Crown Ethers with Podand Arms by Electrospray Ionization. Eur. Mass Spectrom. 1999, 5, 81-88. (g) Shou, W. Z.; Browner, R. F. Evaluation of Crown Ether Complexation for Elemental Electrospray Mass Spectrometry. Anal. Chem. 1999, 71, 3365-3373. (h) Allain, F.; Virelizier, A. H.; Moulin, C. M.; Jankowski, C. K.; Dozol, J. F.; Tabet, J. C. Electrospray-Mass Spectrometric Studies of Selectivity of Alkali Metal Cations Extractions by Calix[4]arene Crowns. Spectroscopy 2000, 14, 127-139.

16. Ralph, S. F.; Iannitti, P.; Kanitz, R.; Sheil, M. M. Determination of Relative Stabilities of Metal-Antibiotic and Metal-Cryptand Complexes by Electrospray Ionization Mass Spectrometry. Eur. Mass Spectrom. 1996, 2, 173-179.

17. Leize, E.; Jaffrezic, A.; Van Dorssaeler, A. Correlation Between Solvation Energies and Electrospray Mass Spectrometric Response Factors. Study by Electrospray Mass Spectrometry of Supramolecular Complexes in Thermodynamic Equilibrium in Solution. J. Mass. Spectrom. 1996, 31, 537-544.

18. Nissinen, M.; Wegelius, E.; Falábu, D. Rissanen K. MelamineInduced Conformational Change of Ethyl Resorcinarene in Solid State. Cryst. Eng. Comm. 2000, 28, 1-3 and references therein.

19. de Koning, L. J.; Nibbering, N. M. M.; van Orden, S. L.; Laukien, F. J. Mass Selection of Ions in a Fourier Transform Ion Cyclotron Resonance Trap Using Correlated Harmonic Excitation Fields (CHEF). Int. J. Mass Spectrom. Ion Processes 1997, 165/166, 209-219.

20. Otwinowski, Z.; Minor, W. Methods in Enzymology, Macromolecular Crystallography, Part A; Carter, C. W.; Sweet, R. M., Eds.; Academic Press: New York, 1997; 307-326.

21. Altomare, A.; Cascarano, G.; Giacovazzo, C.; Guagliardi, A. SIR92-A Program for Crystal Structure Solution. J. Appl. Crystallogr. 1993, 26, 343-350.

22. SHELXL97-Programs for Crystal Structure Refinement. Sheldrick, G. M. Institüt für Anorganische Chemie der Universität, Göttingen, Germany, 1998.

23. Shivanyuk, A.; Rebek, J., Jr. Reversible Encapsulation by Self-Assembling Resorcinarene Subunits. Proc. Nat. Acad. Sci. U.S.A. 2001, 98, 7662-7665. 